\title{
Correction to: Female breeding dispersal to higher quality habitats in a philopatric top predator
}

\author{
Andreas Otterbeck $^{1,2}(\mathbb{1}) \cdot$ Andreas Lindén $^{3} \cdot$ Ruslan Gunko $^{1,4} \cdot$ Eeva Ylinen $^{5} \cdot$ Patrik Byholm $^{1,6}$
}

Accepted: 27 January 2022 / Published online: 14 February 2022

(c) Deutsche Ornithologen-Gesellschaft e.V. 2022

Correction to: Journal of Ornithology (2022) 163:83-92

https://doi.org/10.1007/s10336-021-01943-4

The authors would like to correct errors in the original publication of the article. The correct affiliation for the co-author Eeva Ylinen is:

Department of Environmental and Biological Sciences, University of Eastern Finland, P.O. Box 111, 80101 Joensuu, Finland.

Also, the correct reference for her earlier work is:

Ylinen E (2008) Individual identification and territory fidelity of Northern Goshawk Accipiter gentilis. Master thesis, University of Joensuu (in Finnish with English summary).

Publisher's Note Springer Nature remains neutral with regard to jurisdictional claims in published maps and institutional affiliations.

The original article can be found online at https://doi.org/10.1007/ s10336-021-01943-4.

Andreas Otterbeck

andreas.otterbeck@novia.fi

1 Novia University of Applied Sciences, Raseborgsvägen 9, 10600 Ekenäs, Finland

2 The Helsinki Lab of Ornithology, Finnish Museum of Natural History, University of Helsinki, Helsinki, Finland

3 Natural Resources Institute Finland (Luke), P.O. Box 2, 00791 Helsinki, Finland

4 Department of Biology, University of Turku, 20014 Turku, Finland

5 Department of Environmental and Biological Sciences, University of Eastern Finland, P.O. Box 111, 80101 Joensuu, Finland

6 Organismal and Evolutionary Biology, University of Helsinki, P.O. Box 65, 00014 Helsinki, Finland 